\title{
Primary Malignant Hemangiopericytoma
}

National Cancer Institute

\section{Source}

National Cancer Institute. Primary Malignant Hemangiopericytoma. NCI Thesaurus.

Code C8710.

A rare malignant mesenchymal neoplasm that is believed to have its orig in in smooth muscle derived pericytes without evidence of metastases. 